\title{
Postindustrial Architecture, Dynamic Complexity and the Emerging Principles of Strategic Design
}

\author{
Leonard Bachman, University of Houston
}




\section{Abstract}

The transition from industrial era society to postindustrial society has shifted architecture away from being a predominantly cultural activity, one that is primarily focused on the physical attributes of a design. The newer architectural orientation leans more toward social ideals and strategic missions. These two perspectives have always coexisted in the discipline and critique of architecture, but the traditional subjugation of strategic concerns is eroding. The two aspects should now be considered in a more explicitly unified and mindful way. In that sense, the transition is not between two factions of practitioners with different philosophies, but between two aspects of thought balanced in some manner by each architect. The ultimate intentions of this paper are first to examine the forces of postindustrial change and then to outline a set of principles which establish strategic design as an architectural activity tantamount to, compatible with, and discursively engaged by physical design.

\section{Introduction}

What are the architectural manifestations of postindustrial civilization? More particularly, how have methodical programming, cybernetics, sustainability, computational optimization, scenario planning, and globalization impacted the milieu of architectural design? Further, how should architects be responding positively to these social, cultural, and technical influences?

\section{Overview and Methodology}

This work argues from an interpretative view of recent history and asserts the emergence of strategic design as a coalescence of design activities that have traditionally been considered as peripheral to the mainstream pursuits. Rationale for this investigation is based on widely recognized transitions from industrial society and its linear, hierarchical, mechanistic thinking to the emerging postindustrial era of deeply interrelated and complex systems. In particular, Daniel Bell's, The Coming of Postindustrial Society (1973), puts the beginnings of this transition in the early 1950's. When compared to parallel events in the course of architectural progress however, it is more appropriate to celebrate William Peña's 1969 Problem Seeking as the beginning of postindustrial architecture. Other pivotal events that lead to this perspective would include Jane Jacob's The Death and Life of Great American Cities (1961), Christopher Alexander's Notes on the Synthesis of Form (1964); Churchman, Ackoff, \& Arnoff's
Introduction to Operations Research (1957); and Rachel Carson's Silent Spring (1962). Using Peña as the tipping point then, everything before 1969 belongs to the age of industrial mechanistic order. Everything after that is part of the new more complex postindustrial age.

\section{Operationalizing the Terms}

Physical Design is discussed here as that conventional and most generally ennobled activity of architecture wherein the aspects of materiality, space, and direct human experience are pursued. In short, Physical Design is how architecture captures materiality and immediacy. Strategic Design, on the other hand, is how architecture embodies human intelligence and foresight. Strategic Design is thus that activity of architecture where programming, planning, sustainability, technology, flexibility, adaptability and a host of other "ability-s" are instilled. These are often assumed to be procedural, expected, and reductively deterministic. In another sense, we can say that physical design is accountable to our impressions and our emotive needs, while strategic design is accountable to our empirical and rational needs. A final defining perspective is that physical design meets the mandates of our shared cultural values and experiences; whereas strategic design responds more to the mandates of our societal needs, rules, and institutions.

Postindustrialism is associated with a fundamental transition in our society's primary means of production. This entails the move away from material goods manufacturing and into the purposeful use of knowledge as the basis of commerce and production of value. Postindustrialism is thus connected to the distinction between strategic and physical design because it marks the point in history at which demands for accurate use of well-ordered information overcame our intuitive abilities to cope with their volume and complexity, as well as with the consequences of error in the accountability of societal needs. As Christopher Alexander (1964) put it:

"The crucial quality of shape, no matter of what kind, lies in its organization, and when we think of it in this way we call it form... Today functional problems are becoming less simple all the time. But designers rarely confess their inability to solve them. Instead, when a designer does not understand a problem clearly enough to find the order it really calls for; he falls back on some arbitrarily chosen formal order. The problem, because of its complexity, remains unsolved." 
Alexander is echoed two years later by Robert Venturi (1966):

"First the medium of architecture must be re-examined if the increased scope of our architecture as well as the complexity of its goals are to be expressed. Simplified or superficially complex forms will not work.... Second, the growing complexities of our functional problems must be acknowledged."

From Postindustrialism as the advent of the complex information age, service industry, and the knowledge worker, this argument next turns to defining the characteristics of that underlying condition of complexity. Here it is useful to remember the distinction of indeterminate, or "wicked," problems of design as described by Rittle and Webber (1973). The characteristics of wicked problems can be briefly described as ill structured problems with incomplete beginning parameters, no consensus about the resources available or the desired outcome, no hope of complete knowledge about the interrelated aspects of the factors involved, and no real stopping point or ultimate means of evaluation. Consequently, each attempt to solve a wicked problem iteratively changes our understanding of what the problem really is and what the solution should be.

Nobel economist Herbert Simon (1991) incorporates this concept of complex problems into his foundation research on organizational and decision making theory. His notion of "bounded rationality" argues that our limited human cognition can never completely digest and optimize the exhaustive details of any problem. Simon defines the appropriate coping mechanism as "satisficing" with decisions that are good enough to achieve acceptable accuracy without the paralysis of waiting for complete and precise information and complete analysis.

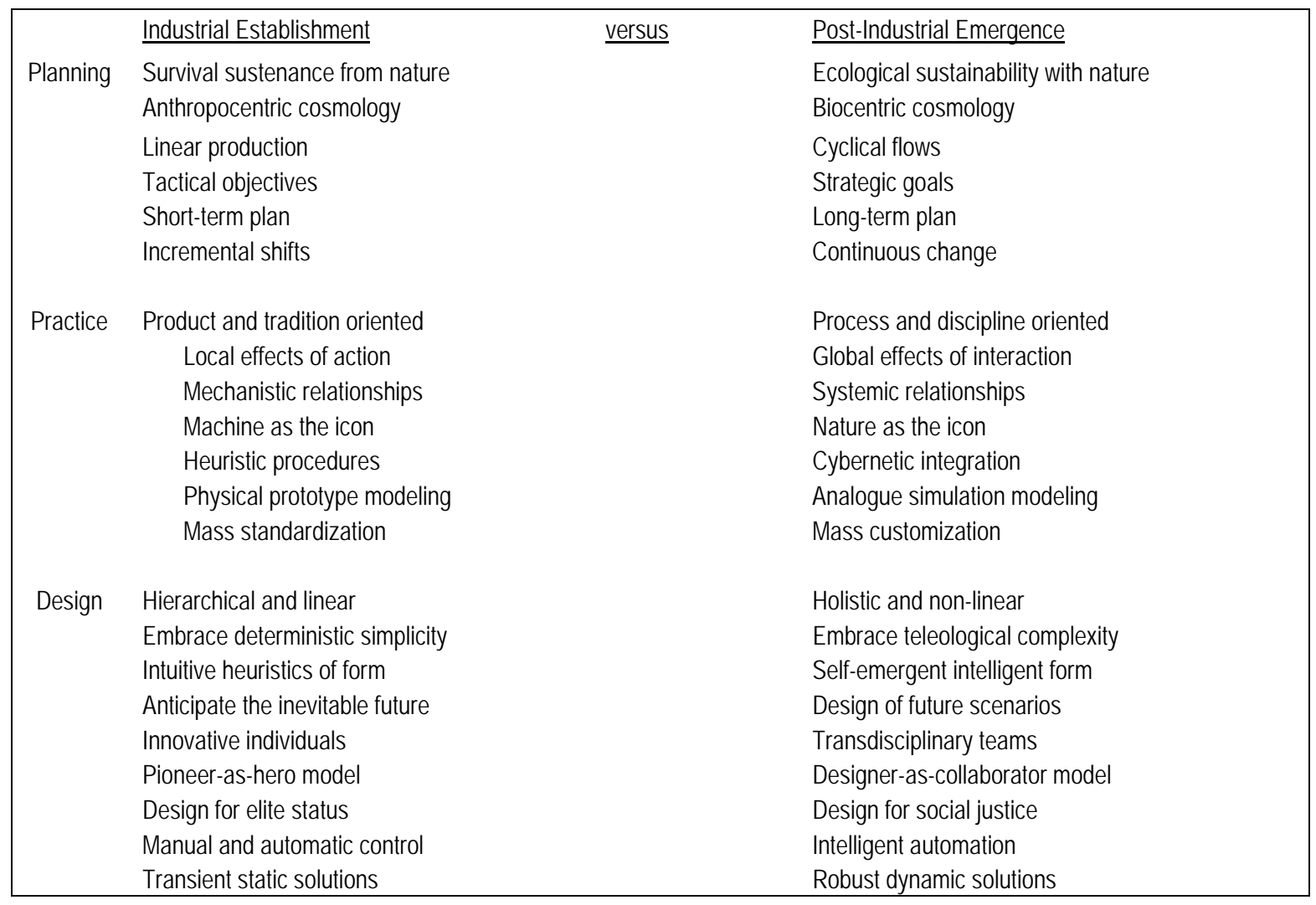

Table 1. The overlay of industrial and

post-industrial society in the context of architecture 
Adjuncts to Simon's "satisficing" strategies have been offered by several writers (e.g., Margolin and Buchannan 1996, Roberts 2000, Bruce and Cote 2003) who collectively observe that artificially taming wicked problems can lead to shallow solutions that disguise the true complexity of a design challenge and sacrifice the potential richness of the solution because they miss the problem's unique essence. Further logic insists that this complexity is in fact the real design arena or so-called problem space of architectural design because it involves the ambiguous regions of possibility rather than deterministic boundaries. To invoke the paradigms of complexity theory, possibility only exists on the edge of chaos, not in the dead stasis of empirical facts. To invoke Coleridge, (1817) "Fancy, on the contrary, has no other counters to play with, but [ready-made] fixities and definites. The fancy is indeed no other than a mode of memory."

\section{Systems, Cybernetics, and Teleology}

So far in this argument, strategic design has been differentiated from physical design by the distinction of how intelligence versus materiality is embodied in architecture. This distinction was then couched in the advent of Postindustrial society and the new epoch of Information. Next, the harnessing of this information was discussed as complex and wicked, leading to the present point of celebrating complexity in order to bring about richness through identifying the unique essence of a situation rather than ignoring Alexander's warning of "arbitrarily chosen form" or Venturi's "superficially complex" ones.

True complexity, as opposed to detail complication, requires a holistic and comprehensive approach to design.

\begin{tabular}{|ll|}
\hline Physics & $\begin{array}{l}\text { Quantum mechanics and the Unified Field } \\
\text { Theory (Bohr, Heisenberg, Hawking) } \\
\text { Non-linear and chaotic systems }\end{array}$ \\
Psychology & $\begin{array}{l}\text { Self actualization and psychosynthesis } \\
\text { Engineering (Maslow, Graf) }\end{array}$ \\
Sociology & Knowledge based culture (Kuhn) \\
Business & Industrial Organization Psychology \\
Medicine & Holistic health and mind/body healing (Chopra) \\
Agriculture & Organic gardening and beneficial insects \\
& (Rodale) \\
Economics & Life-cycle costs and externalized accounting \\
& (Henderson)
\end{tabular}

Table 2. Postindustrial professions (from Bachman 2003)
In other words, the richness of complexity will lead us to seek systemic solutions rather than symptomatic ones. We expect this approach from other professions that serve society, and the social needs for systemic architecture are no less important and no further from our grasp (Table 2). By way of example here, a doctor who dispenses aspirin for a headache is taking a symptomatic and mechanistic approach to the problem of patient health, an approach that is content with quick gratification if the pain diminishes. By contrast, a doctor who asks if you have had your eyes checked lately is trying to find the underlying systemic cause of the malady and thus invoke a real cure.

\begin{tabular}{|ll|}
\hline $\begin{array}{l}\text { Dynamic Complexity } \\
\text { Problems }\end{array}$ & Detailed Complexity Problems \\
Different effects at & Find best combination of many \\
different scales & possibilities \\
Interventions lead to & Complicated array of details \\
counterintuitive results & \\
There is a lag between & Combinatorial selectionof \\
action and reaction & optimum choices \\
$\begin{array}{l}\text { Factors are deeply } \\
\text { interactive }\end{array}$ & Factors respond mechanistically \\
$\begin{array}{l}\text { Deal with organized and } \\
\text { interrelated flows } \\
\text { Involve self-correcting } \\
\text { cyclical feedback loops } \\
\text { Outcomes are probabilistic } \\
\text { rather than certain }\end{array}$ & Deal with static and predictable \\
flows & Outcomes are mechanistic \\
\hline Table 3. Dynamic versus Detailed Complexity
\end{tabular}

Table 3. Dynamic versus Detailed Complexity

In architecture, the best example of systemic and holistic design inquiry has been driven by demands for a sustainable approach to the built environment. Carson's Silent Spring (1962) has already been mentioned, but the more relevant work is perhaps that of Patrick Geddes and Lewis Mumford who seem to have co-invented the terms "paleotechnic" and "neotechnic" to describe what we now understand as industrial and postindustrial attitudes toward natural resources (Mumford, 1934; Novak, 1995).

Systems theory is not a new or novel idea in architecture of course, but rather one which needs to be reconsidered, especially if the model of sustainability is to be more than a gesture about being green and efficient in the way that modernism began as a gesture about machine production. 
It must be emphasized that this is not a speculative, conjectural, or purely theoretical discussion about fractals or other popularized aspects of chaos theory. Complexity is real and it is the best perspective we have today on how the everyday world around us actually operates. The systematic principles involved in dealing with complexity have been applied to common practice in every conceivable discipline and profession. The foundational literature supporting complexity is enormous and pervasive. Any brief survey of contemporary business management articles for example, will illustrate that systems thinking and cybernetic processes are being brought to bear on even the most practical and pragmatic of problems.

At this point it is also useful to distinguish dynamic complexity of interrelated factors from the common "piled up" complexity of information overload. That lesser sort of complication only leads to what Peter Senge has called "detail complexity." Senge differentiates "needle in the haystack" detail complexity from "How did that happen?" dynamic complexity in the following ways (Table 3).

\section{Conceptual Models}

To help visualize the relation of physical and strategic design in a positive and harmonious way, consider the model of the human mind. We know that the left brain is associated more with rational analytical objective thinking and the right brain more with holistic subjective synthetic workings. In between there is an integrating corpus callosum that keeps the [communication flowing between the two hemispheres] neural network flowing. Nowhere however, is there a higher controlling function that unifies the workings of the brain organ into mindful consciousness. The mind is self emergent, a spontaneous and teleological product of the complexity of its parts. Without the emergence of the mind life would be that of a mechanistic Frankenstein who has all the pieces but lacks vital animation.

In Complex Patterns: The Self Organization of Brain and Behavior, Richard Kelso (1995, pg 9) extends a general framework connecting brain, mind, and behavior. In so doing, he reminds us that the brain is just an organ, and that the mind is something else entirely. In place of the classical division between right and left brain mental activity, Kelso gives us insight as to the emergence of mind. The difference is that brain activity is physiological and mechanical whereas the mind is a richly complex set of interconnections and interactions among the brain parts. More importantly, there is no hierarchy or manager in this process; it is completely self-organizing:

"... there is no reference state with which feedback can be compared and no place where comparison operations are performed... there are no feedback-regulated set-points or reference values as in a thermostat. Hence, the questions of who sets the reference value, who programs the computer, who programs the programmer, and so on do not even arise. Self-organizing systems have no deus ex machina, no ghost in the machine ordering the parts."

To apply the analogy, mindful architecture has left-brain strategic design function and a right-brain physical design function. Without the emergence of holistic mindfulness from these two organ parts, there is no higher order of architecture distinct from mere buildings.

A second conceptual model is offered by the double helix DNA molecule. This is also where the propositional theme of this paper enters. Rather than the conventional notion of architectural design as a single thread of right brained physical design as the mainstream activity, this model suggests that the strategic thread and the physical thread are intertwined and form a complete structure of complimentary parts. And the rope is always stronger than the sum of its threads.

To achieve these conceptual models, it is necessary to accept strategic design as equal, or tantamount, to physical design. This is not a dichotomous proposition however, no more than arguing that the mind is emergent from its constituent parts or that the health of both aspects are essential to the whole. All works of architecture (and architects themselves) are comparatively more right brain oriented or left brain oriented than others, but all along that continuum, at each point and every example, there is ostensibly, still the accomplishment of a full mindfulness. We only need reexamine our notions of attribution for how this mindfulness was achieved to recognize the complimentary and inseparable nature of physical and strategic design. These conceptual models address that by offering a framework wherein physical design is formed by that thread of architectural work associated with materiality, space, and direct experience. A second thread is then added by collecting all the strategic design activities that are usually considered as individual adjuncts in support of 
physical design, namely: programming, planning, constructability, serviceability, sustainability, flexibility, agility, adaptability and so on.

\section{The Bridges}

What is the corpus callosum of architectural mindfulness that connects physical and strategic design? We are not asking here how to animate complex order, which is only part of our faith in the higher power of nature and creation. We can ask however how to engage that order and achieve mindfulness through a practice of architecture that bridges our cognitive strands of DNA, the physical and the strategic. Here we are at the gate of old debates: form versus function, art versus science and so forth. Hopefully however, this present discussion has already framed those debates as a dynamic discourse between two equal aspects.

The German philosopher Hans-Georg Gadamer (19002002) offers the bridge of hermeneutics. In his seminal Truth and Method (1960), Gadamer acknowledged that the two pursuits are often in conflict but resolves [resolved] them with the thesis that both sides are correct, but neither is complete.

Hermeneutics is the philosophy and science of interpretation. The etymology of the term derives from the legendary Greek figure Hermes, who was said to carry messages from Olympus and deliver them to mortals. Over time, the term was applied to exegesis in the interpretation [??] of biblical text and finally to interpretation of text in general. In current thinking, hermeneutics involves a cycle of observation, preliminary understanding, trial of an adductive and holistic proposition, observation of appropriate fit, followed by a new understanding and reinterpretation of the situation, and then by iterative repetitions of the cycle converging in a final satisfactory level of understanding.

Figure 1 illustrates the hermeneutic cycle. Imagine that the outer edge of the spiral is the beginning of a project and the completion of the project is at the center of the spiral at a kind of gravitational singularity or, to romanticize a term from complexity theory, a Strange Attractor.

Each winding of the spiral is a cycle of hermeneutic interpretation. The circular orbit of the path, as opposed to a straight line deterministic solution, is dynamically balanced between two forces: the centrifugal force of asking "Why not?" which expands the orbit by resisting the final solution singularity, and the centripetal force of asking "So what?" which degrades the orbit until it is overcome and "satisificed" by the strange attractor.

At another scale, imagine that the trace of the spiral is not a line but a twisted thread, a thread which is wound from multiple strands. Each single strand of the thread-path is in turn a double helix much like the double helix of DNA. Each strand is a pair of complementary thought lines: micro-scale details and macro-scale ordering, empirical and poetic truths, strategy and form, and so forth. Finally, each of these double helix strands is internally bound together by interaction, just as the left brain and the right brain are integrated by the corpus callosum.

To summarize the hermeneutic bridge, we can say that architecture is congruent with the interpretive and assimilative method of hermeneutics because of the...

- Implicit nature of design knowledge wherein understanding and interpretation are superior to empirical fact,

- Adductive basis of hermeneutics which is already native to design thought,

- Oscillating engine of expansion and contraction in design between "Why not?" and "So what?" thinking,

- Pluralistic perspectives that designers maintain about what is good architecture,

- Divergent perspectives of multiple stakeholders involved in architectural projects,

- Multiple scales of overarching order at the macro inductive scale and integrity of individual details at the deductive micro scale,

- Indeterminate or "wicked" nature of design in which there can be no linear or procedural recipe for solution,

- Cybernetic nature of information feedback systems in complex problems of design,

- Principles of natural teleology, which cybernetics and Aristotle describe as the Final Cause and,

- Incomplete nature of knowledge and finite limits of human understanding in any complex problem, conditions leading to Herbert Simon's description of "satisficing" as the goodenough solution in favor of the perfect one.

Beyond hermeneutics, Gadamer $(1986,67)$ also offers another bridge between strategic and physical design 
pursuits in his perspective on aesthetics:

"In the beautiful presented in nature and art, we experience this convincing illumination of truth and harmony, which compels the admission: This is true. The ontological function of the beautiful is to bridge the chasm between the ideal and the real."

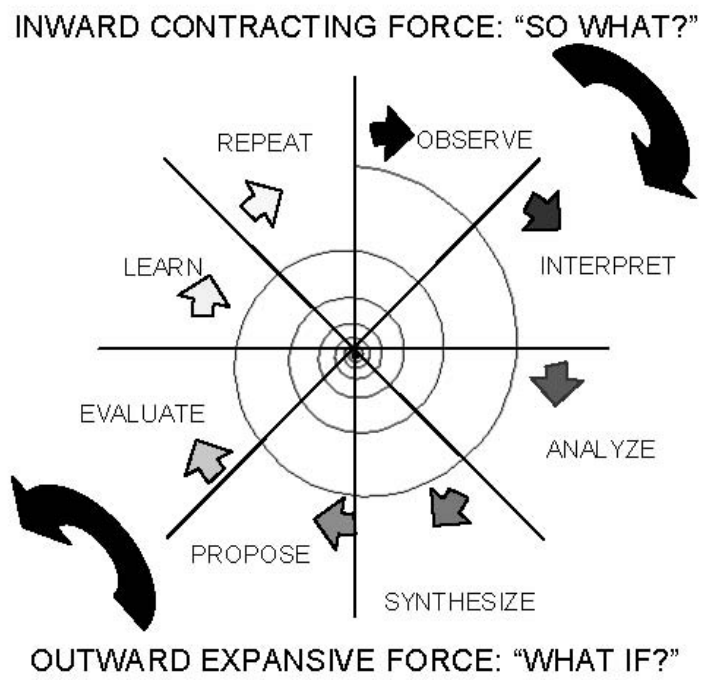

Figure 1: The Hermeneutic Spiral

Gadamer is joined in this aesthetic bridge building by Roger Scrutton (1979):

Aesthetic consideration conveys the interdependence of our sense of beauty and our intellectual understanding.

A third bridge, located very near the second, is that of intellectual beauty, where the sublime values of architecture are achieved by connecting our understanding of the intelligence vested in a design with our appreciation of its physical and experiential character. We find intellectual beauty in the subtle moves of a chess game, in the sleek lines of a race car, in the power of a mathematical equation, or in the intricate unplanned workings of nature. None of these aesthetic appreciations originate from physical appeal. We should find this same sort of explicit aesthetic appreciation for the strategic aspects of architecture. The poets Keats and Shelly would add that not only is "truth beauty and beauty truth," but also that the search for truth is itself driven by aesthetic motivations.
To summarize this section, intellectual beauty, hermeneutic discourse and aesthetic philosophy each offers a positive way of considering strategic design and physical design to be equal parts of architecture. Hermeneutics takes complexity and contradiction into an iterative cycle of discourse between incomplete perspectives. Aesthetic value connects our intelligent understanding with our spontaneous appreciation without giving the idea of beauty to one exclusive of the other. Intellectual beauty captures our direct enjoyment of embodied intellect. These are the corpus callosum of mindful architecture.

\section{The Evidence}

While the various elements of strategic design are seldom thought of as a collective branch of architectural design, they do have individual proponents and a large body of practitioners. Until recently however, there has been little recognition or ennoblement of this wing of the profession. This relative obscurity is probably a product of the nominally expected level of thinking through practical and functional criteria of design problems. As long as the problems were perceived to be simple and determinate this was not an exceptional circumstance.

As postindustrial complexity has gained more influence on architectural design, the presumption of clear thinking about functional problems has given way to deeper inquiry. There are at least three obvious manifestations of this in current practice. The first is Post Occupancy Evaluation (POE) where the architect's intentions are both verified as having been attained and validated as having been appropriate in the first place by the direct experience of the building users. The second is Continuous Commissioning (Cx) which matches the actual control and operation of the building to its actual use in occupancy, and periodically readjusts for changes in either side of the equation. Finally, there is Leadership in Energy and Environmental Design (LEED ${ }^{\mathrm{TM}}$ ), which measures any number of accountability factors in long term building performance.

\section{The Principles}

Table 1 listed philosophical principles of postindustrial architecture in contrast with those of the preceding industrial era. This final section concludes the discussion by extending and reiterating the major points into an outline set of principles of strategic design. They are arranged here from roughly the most abstract structural thinking to the 
most procedural.

Celebrate complexity rather than trying to tame it. Any attempt to tame complexity risks becoming [??] reductive and simplistic, thus sacrificing the real essence and richness of the design challenge. Use complexity to reveal and instill richness.

Cycle between global interaction of interrelated effects and local action of immediate reality. On one hand, material selections will involve detailed complexity. These details act at the local level of human perception and their operations are relatively intuitive. On the other hand, thermodynamic stability, construction sequence, ecological balance, occupant satisfaction, flexible expansion, and most other problems of strategic design will always entail feedback loops and dynamic complexity: pushing on one will change the others. Dynamic systems operate at non-local levels of reality which are not directly discernable to human perception. Using local scale perceptions to make non-local scale decisions can therefore lead to unpredictable, unintentional, and entirely dysfunctional results, even if those shortcomings are not revealed in the initial stages of operation. Physicist David Bohm (1990) thought of these two scales as the non-local Implicate Order and the local Explicate Order. As coauthor David Peat (1987) puts it:

What we take for reality, Bohm argues, are surface phenomena, explicate forms that have temporarily unfolded out of an underlying implicate order. Within this deeper order forms are enfolded within each other so systems which may be well separated in the Explicate Order are contained within each other in the Implicate Order. Within the Implicate Order one form can be both interior and exterior to another.

Identify the uniqueness. Ultimately every project has a personality as individual and complex as that of any single person. In the teleological sense, this essence is also the root of Final Cause, or the acorn that will become the oak tree.

Separate the known, the unknowable, and the potentially knowable as three regions of knowledge. Delineate these as regions of given boundaries, irrelevant noise, and productive exploration, respectively. Don't waste design resources trying to defy the inevitable or the unknowable, but rather focus on the ambiguous region where knowable coalescence is more pregnant with possibility.
Plan future scenarios. As computing pioneer Alan C. Kay says, "The best way to predict the future is to invent it." We should not act as if the future was unfathomable or that it is an inevitable mechanistic extension of present trends. Decide where the project should go over time and map the plan for getting there along with its benchmarks and contingencies. Consider the scenario planning techniques devised by Royal Dutch Shell in the 1960s as they are presently being used in the corporate world.

Consider a building as a set of flows. Rather than consider the building as a static object, it is possible to think of it as a web of interacting flows. Steven Groák (1992) imagined that a building might be considered as a system of flows: people, light, air, heat, information, products, gravity, sound, and so on. The building's components then assume description as reservoirs, conduits, capacitors, and to use Norberg-Schulz's original terms from his Intentions in Architecture: filters, barriers, and switches.

Distinguish systemic solutions from symptomatic ones. Ask if each design move is addressing underlying issues or merely making artful gestures that resolve formal decisions. Differentiate radical influences from secondary ones. Sustainability for example is a radical concept whose characteristics cannot be added on as secondary to other concerns. See John Tillman Lyle (1994) for a discussion of the radical principles of sustainable design such as "Use form to channel flow."

Use bridges to unify the strategic and physical aspects of design into complete mindfulness. Hermeneutic discourse, aesthetic unity of "the real and the ideal," and intellectual beauty should be continually engaged.

Understand the mission components. Don't confuse the objectives with the goals, the tactics with the strategies, or the wants with the needs.

Distinguish between facts, opinions, and ideas. Avoid misdirection. Along the same lines, don't confuse knowledge with understanding, or data with information. See Heath (1991).

Seek collaborative discourse. Incorporate as many different viewpoints and stakeholder concerns as possible into the influential thinking and evaluative reviews. 
Beware of hidden agendas. Look for expectations that are not being made explicit.

Adapt benchmarks from relevant existing projects. There is no sense in trying to reinvent the wisdom of architecture with each new project. Ground the project in a bounded range of reasonable and realistic expectations.

Find the drivers. Drill down to what matters and focus on decisions that have the most impact.

Identify the right scale of detail for the level of decisions being currently made. Don't work with pine cone sized factors when you are still wondering about the pine tree sized one.

\section{Acknowledgments :}

The background thinking for this paper and many of its details are part of an ongoing research project undertaken by the author and Kurt Neubek, FAIA. Mr. Neubek is Associate

Principal and Director of Strategic Services at

PageSoutherlandPage, Houston, Texas.

References :

Alexander, Christopher. 1964. Notes on the synthesis of

form. Cambridge, Mass.: Harvard University Press,

Alexander, Christopher. 1966. From a set of forces to a form. In The man-made object. Kepes, Gyorgy ed. New York, G. Braziller

Bachman, Leonard R. 2003. Integrated buildings: the systems basis of architecture, New York: Wiley.

Bell, Daniel. 1973. The coming of post-industrial society; a venture in social forecasting. New York: Basic Books.

Bohm, David and Peat, David F. 1987. Science, order and creativity. New York: Bantam Books.

Bohm, David. 1980. Wholeness and the implicate order, London: Routledge and Kegan Paul.

Bruce, Raymon R. and Cote, Nathan. 2002. Taming wicked problems: theory and practice, The Public Manager, Fall.

Carson, Rachel. 1962. Silent spring. Boston: Houghton Mifflin.

Churchman, C. West, Ackoff, Russell L. and Arnoff, E. Leonard. 1957. Introduction to operations research. New York: Wiley.

Gadamar, Hans-Georg. 1986. The relevance of the beautiful and other essays. Cambridge; New York: Cambridge
University Press.

Gadamer, Hans-Georg. 1975. Truth and method. New York: Seabury Press.

Groák, Steven. 1992. The idea of building : thought and action in the design and production of buildings. London ; New York : E \& FN Spon.

Heath, T. 1991. What, if anything, is an architect? Melbourne: Architecture Media Australia.

Jacobs, Jane. 1961. The death and life of great American cities. New York: Random House.

Kay Alan C. 1989. Stanford Engineering, Volume 1, Number 1, Autumn, pg 1-6.

Kelso, Richard. 1995. Dynamic patterns: the self organization of brain and behavior. Cambridge, Mass.: MIT Press.

Lyle, John Tillman. 1994. Regenerative design for sustainable development. New York: John Wiley.

Margolin, Victor and Buchanan, Richard. eds.1995. The idea of design. Cambridge, Mass: MIT Press.

Mumford, Lewis. 1934. Technics and civilization. New York: Harcourt, Brace \& World.

Norberg-Schulz Intentions in architecture. 1965. Cambridge, Mass., MIT Press.

Novak, Frank G, ed. 1995. Lewis Mumford and Patrick Geddes: the correspondence. New York: Routledge.

Peat, David F. 2005. Non-locality in Nature and Cognition.http://www.fdavidpeat.com/bibliography/essays/nat-cog.htm (accessed January 27, 2005).

Peña, William. 1962. Problem seeking: new directions in architectural programming. Houston: Caudill Rowlett Scott.

Rittel, H., and Webber, M. 1973. Dilemmas in a general theory of planning" Policy Sciences 4:155-169.

Roberts, Nancy. 2001. Learning from international public management reform, 11(B): 353-375.

Scruton, Roger. 1979. The aesthetics of architecture. Princeton, NJ: Princeton University Press.

Senge, Peter M. 1990. The fifth discipline: the art and practice of the learning organization. New York: Doubleday.

Simon, Herbert A. 1990. Bounded rationality and organizational learning, Organization Science, 2 (1): 125134.

Venturi, Robert. 1966. Complexity and contradiction in architecture. New York: Museum of Modern Art; Doubleday. 